\title{
Moral duty, warm glow or self-interest? A choice experiment study on motivations for domestic garbage sorting in Italy
}

\author{
Antonio Massarutto, Francesco Marangon, Stefania Troiano, Marinella Favot \\ University of Udine Department of Economics and Statistics (DIES), Via Tomadini 30/A, 33100 Udine, Italy
}

\section{A R T I C L E I N F O}

\section{Article history:}

Received 5 June 2018

Received in revised form

11 October 2018

Accepted 12 October 2018

Available online 17 October 2018

\section{Keywords:}

Choice experiment

Warm glow

Municipal solid waste

Latent class model

Recycling behaviour

\begin{abstract}
A B S T R A C T
Behavioural and mainstream environmental economics have proposed alternative explanations for individual motivations behind environmentally relevant activities, leading to different recommendations for policymakers. Separate collection of different types of municipal waste represents a popular field of application. In this paper, we exploit the results of a choice experiment study conducted on a representative sample of 1010 Italian households, aimed at understanding the relative weights of economic and non-economic motivations. The results show that the mean willingness to pay for separate waste collection is $€ 77 /$ year per family, which is an adequate empirical estimate of the warm glow effect of recycling. However, the four identified latent classes reveal individuals with fairly opposite motivations. This finding can be interpreted as the fact that the two types of motivations (economic and noneconomic) do not add up but tend to cancel each other. The concept of latent classes applied to environmental economics is novel and suggests distinct typologies of individuals. More importantly, these groups of individuals are likely to react differently to alternative policy instruments. Therefore, instead of designing waste management policies based on the assumption that behavioural responses are stereotyped, policymakers should adopt a more complex set of policy instruments that target different groups of individuals, with appropriately chosen incentive schemes.
\end{abstract}

() 2018 Elsevier Ltd. All rights reserved.

\section{Introduction}

Mainstream environmental economics rests on the basic idea that economic incentives shape individual behaviour in most fields, including resource conservation. With environmental impact being fundamentally encompassed in the concept of negative externality, the policy scheme that arises is invariably the internalisation of environmental costs through various kinds of economic instruments. These instruments are aimed at leveraging self-interest to alter the individual payoff of alternative behaviour.

More recently, economists have paid more attention to noneconomic motivations behind human behaviour (Tong et al., 2018). The level of knowledge and awareness of environmental problems, social norms, peer influence, personal beliefs, individual ideology and altruism also matter and are probably equally or even more important than purely utilitarian considerations (Wang et al.,

\footnotetext{
* Corresponding author.

E-mail addresses: antonio.massarutto@uniud.it (A. Massarutto), francesco. marangon@uniud.it (F. Marangon), stefania.troiano@uniud.it (S. Troiano), marinella.favot@uniud.it (M. Favot).
}

2016).

A common key to this insight is represented by the bulk of research that (borrowing from the closely related social sciences) has criticised the basic assumptions of rational choice theories. A mounting number of applied studies have investigated individual behaviour towards the environment from the most disparate methodological and scientific perspectives. Individual and household participation in waste reduction and recycling offers a suitable field of the application of such theories. Although this body of literature has added significant new contributions, it has rarely led to a combined and systematic consideration of either economic or non-economic motivational perspectives in order to derive insights for policymaking. Furthermore, some disputes have arisen about the ways that economic and non-economic aspects interact (Van den Bergh, 2008).

Our study intends to contribute to this field of research through the application of a rigorous and tested economic valuation methodology, with the aim of investigating (1) the relative importance of economic and non-economic motivations, (2) how structural factors regarding municipal solid waste (MSW) management affect the motivations and finally, (3) how individuals 
evaluate alternative ways to improve the quality of MSW management, with a more or less direct focus on separate collection.

This paper is organised as follows: section 2 reviews the relevant literature, section 3 presents the material and methods, followed by section 4 , which covers the results and discussion section. Finally, section 5 presents the conclusions and the policy implications of the research.

\section{Literature review}

Household collaboration is crucial in any waste separation system. Although most people agree that waste reduction and recycling are beneficial practices, sorting waste in domestic premises is not a pleasant activity. It implies varying efforts (involving both economic and behavioural costs, represented by space occupation, time use, self-sacrifice and inconvenience), depending on the type of waste and the intensity of recycling. The standard theory of public goods suggests that rational individuals would take a free ride (i.e., fail to contribute adequately, expecting that others will do so), leading to systematic under-provision.

Nevertheless, evidence shows that people actually recycle (Bruvoll et al., 2002). This practice may depend on extrinsic motivations, such as compliance with regulations (da Cruz et al., 2014) and social norms (Rege, 2004), or on intrinsic ones, such as moral duties (Chan and Bishop, 2013) or economic benefits (Halvorsen, 2012). Although the economic theory has widely investigated recycling behaviour, it has not reached unanimous conclusions about how different motivations interact with one another.

The first type of possible motivation concerns the economic benefits that may result from the reduction of waste management costs (Struk, 2017), recycling subsidies (Viscusi et al., 2011), or the threat of fines and penalties. Ferreira and Maques (2015), for example, assessed monetary values of environmental services, such as selective waste collection using the contingent valuation method (CVM). Despite theoretical expectations, the evidence in support of the relevance of economic incentives on its own is not strong like in the case of cost saving without other incentives (Kirakozian, 2016) or in case of economic incentives without effective monitoring (Van den Bergh, 2008).

The second type of motivation rests on intrinsic utility. Behavioural economics suggests that households have both intrinsic and extrinsic values in relation to environmental public goods (Kirakozian, 2016). Cecere et al. (2014) distinguish between extrinsic motivations (social norms) and intrinsic motivations derived from a person's attitude, which include altruism and "warm glow" (Andreoni, 1990). This concept captures the idea that individuals derive an intrinsic utility from open-handedness and altruism. In practice, the warm-glow model brings moral motivations into a utilitarian framework, assuming that compliance with ethical norms generates a private good. For example, in a case study involving mobile collection in China, citizens engaged in environmental protection activities show a statistically higher participation percentage than those who are not involved (Tan et al., 2018).

An important issue concerns the ways that different motivations interact. Many studies consider both economic and non-economic aspects as providing additive motivations (crowding-in) (e.g. Abbott et al., 2013; Cecere et al., 2014). Other studies report evidence of a possible trade-off and crowding-out effects (Heller and Vatn, 2017; Varotto and Spagnolli, 2017).

Many factors contribute to shaping the social norms, such as imitation of peers (Abrahamse and Steg, 2013), the behaviour of immediate neighbours (Shaw, 2008), parental example (Matthies et al., 2012) and perceived effectiveness (Wan et al., 2013). Beliefs, level of knowledge and engagement also matter. Other studies find that the relative importance of personal values and social norms depends on the individual cost of recycling. Making sorting more economical (e.g., by providing more accessible and comfortable collection services) is a powerful way to strengthen social norms (Andersson and von Borgstede, 2010; Sidique et al., 2010) but can generate crowding-out effects as well (Brekke et al., 2003).

Recycling is a seemingly multiform behaviour whose determinants require separate analysis. For this reason, this present study adopts the choice experiment (CE) method. This method values non-market benefits through the creation of hypothetical markets (Adamowicz et al., 1994, 1998) to elicit people's willingness to pay (WTP) for each of the specific attributes that characterises an economic good (Boxall et al., 1996). The theoretical background of the CE method comprises the Lancaster (1966) model of consumer choice and its econometric basis on the random utility theory (McFadden, 1974). Lancaster suggests that individuals derive utility, not from the goods themselves, but from their separable attributes. With respect to the previously mentioned more traditional CVMs, the CE model is better because it offers the possibility to refer individual WTP to each attribute (Hanley et al., 1998, 2001).

Furthermore, the CE model is preferable because it allows researchers to characterise clusters of individuals (latent classes [LCs]) showing comparable and regular similarities. Since its development, the technique has been refined and introduced into a number of fields of valuation, such as MSW (Czajkowski et al., 2014; Klaiman et al., 2016) and management preferences (Jamal, 2006; Pek and Jamal, 2011). These studies offer empirical evidence that recycling provides a net source of utility (Sakata, 2007).

However, only a few studies have applied the CE model to assess external costs derived from the perceived environmental impact of disposal facilities (Jin et al., 2006) and to detect the magnitude of negative reactions against locating facilities near respondents' backyards (Giaccaria and Frontuto, 2012) or in ecologically sensitive sites (Sasao, 2004). To our best knowledge, only Czajkowski et al. (2017), with their case study in Poland, have so far applied the CE to jointly investigate the impact and the interaction of economic and non-economic motivations on the choice of waste management contracts. They find a preference for home sorting due to the prevalence of a "self-image" effect (on individual ethics), prevailing on both genuinely economic motivations and "social image" (compliance with social norms). However, their study does not further explore the possible existence of LCs.

\section{Material and methods}

As noted, despite the wide diffusion of CE-based waste management studies, only a few have explicitly addressed the motivations for recycling. None has attempted to provide a comprehensive analysis of different characteristics of the waste recycling service and to estimate the WTP for each of its attributes. Our study aims at contributing its results to fill this gap. To achieve this aim, we conducted an online questionnaire survey and used a CE to investigate the respondents' WTP for the waste collection service organised in different ways, so as to capture the relative importance of each attribute.

We collected the data by means of the questionnaire that was adapted from previous studies in other national settings (e.g., Aadland and Caplan, 2006a, 2006b) and through several focus group discussions among a number of stakeholders (i.e., agencies involved in waste collection and waste treatment services, government officials, some environmental experts and local residents).

The questionnaire consists of three sections. The first one starts with an introductory text explaining the study's aims. A few types of socioeconomic data are requested (gender, education, age, household members, work position, place of residence, etc.). The membership of a family component in an environmental non- 
governmental organisation (NGO) can be an indicator of the household's commitment to environmental issues. A few questions aim to identify some key characteristics of the waste collection service (e.g., method [drop-off versus kerbside], the presence of a disposal facility in nearby areas), while further information on local municipal waste (MW) management systems has been extracted from official national databases and is based on the intensity of recycling and disposal solutions.

The second section investigates the motivations for domestic sorting of waste and a series of subjective assessments. We propose two economic motivations for recycling, a private one (i.e., reduction of household bills) and a public one (i.e., reduction of total costs for the community as a whole), as well as a moral justification on the grounds of environmental protection. We investigate the respondents' perceptions about their neighbours' and peers' commitment. The end of this second section is preparatory to the CE study and poses a number of questions that crosscheck personal assessments and economic considerations. It starts by asking the respondents about their willingness to accept (WTA) a free provision of an MW service in exchange for the availability to host a new MW treatment facility. On the opposite side, a question in the CE investigates the participants' WTP for sending MW to another country.

The third section displays the proper CE, which is designed to analyse consumer preferences regarding alternative solid waste management programmes. Since in a CE, it is assumed that a good/ service can be described by its characteristics (attributes), in the present context, the waste management service can be viewed as a collection of its attributes, from which consumers derive utility.

In accordance with our research objectives, five main attributes of a waste management service have been defined after a focus group screening, as follows: (1) type and frequency of waste collection, (2) location of disposal site, (3) charging methods, (4) rate of total recycling and (5) yearly garbage fee per household. Table 1 lists the attributes and their levels in detail.

Regarding the first attribute, we focus on three waste collection systems: (1.1 and 1.2) kerbside collection, whose frequency is every five or three days, respectively, and (1.3) drop-off bins located in some areas of the street at a convenient distance. The second attribute concerns the location of the disposal site, which could be in Italy or abroad. This attribute aims to verify the existence of the "not in my backyard" (NIMBY) effect or conversely, the possible desire for and the public attitude towards self-sufficiency in MW treatment. Concerning the charging method (the third attribute), we distinguish between two options: the fee weighted by the house value and the number of household members and the fee based on the weight amount of the unsorted waste collected. Under the first system, residents pay the same amount of money regardless of the amount of waste they produce, but the fee increases according to the house value and the number of family members. With the second method, residents pay only for the amount of unsorted waste they generate. During the focus group discussion for the questionnaire testing, the participants revealed the rate of the total recycling of MW (the fourth attribute) as an important aspect as well, stated as low, medium and high levels of the generated amount of waste (Kinnaman, 2014). The fifth attribute used in this $\mathrm{CE}$ is the yearly cost of the waste management system per household that is based on current MW management costs for different waste disposal services in Italy (ISPRA, 2013). The prices range from $€ 100$ to $€ 230$ per household per year.

An orthogonal fractional factorial design was generated with SPSS $^{\circledR}$ software. The generated design consisted of 18 profiles (options) organised into six choice sets. Each respondent had six choice situations with three profiles each, plus the opt-out alternative ("none of these") (Table 2). Each option had a graphical presentation to facilitate the response. According to their preferences and budget constraints, simulating a real purchase situation, the respondents were asked to choose among three types of waste management service.

In a previous pilot study, the questionnaire was administered to 50 respondents to test the survey wording and reveal misinterpretations of the questions. After completing the questionnaire, the respondents were interviewed to collect their feedback on any difficulty they experienced in the choice tasks. Following Aadland and Caplan (2006a) suggestion, all interviews were preceded by a short "cheap talk" introduction to the CE scenarios, aimed at providing the proper context, avoiding misunderstandings about the scope of the survey and minimising the risk of a hypothetical bias. Moreover, every CE attribute had a corresponding "help text" to provide the respondents with additional information to facilitate their survey completion.

The final survey was conducted in Italy in March 2014, using an online questionnaire with the support of a professional company specialising in opinion surveys. The questionnaire was administered to a panel as a web survey, not as a computer-assisted personal interview; in fact, each respondent completed the questionnaire on his/her own computer without any external assistance. A sample comprising 1010 individuals (who paid the

Table 1

Attributes and corresponding levels of the choice experiment design.

\begin{tabular}{|c|c|}
\hline Attributes & Levels of attributes \\
\hline 1) Waste collection management and frequency & 1.1 Kerbside collection every five days; 1.2 kerbside collection every three days; 1.3 open-access street bins \\
\hline 2) Location of disposal site & In Italy; abroad \\
\hline 3) Charging method & Flat fee based on the house value and the number of household members; fee based on the amount of waste collected \\
\hline 4) Rate of recycling & High; medium; low \\
\hline 5) Service fee per household ( $€ /$ year) & $100 ; 150 ; 230$ \\
\hline
\end{tabular}

Table 2

Example of a choice set (translation).

\begin{tabular}{|c|c|c|c|c|}
\hline Choice set 1 & A & B & $\mathrm{C}$ & $\mathrm{D}$ \\
\hline Annual fee & $€ 100$ & $€ 150$ & $€ 230$ & None of these \\
\hline Waste collection & Open-access street bins & Kerbside every five days & Kerbside every three days & \\
\hline Location of disposal site & Italy & Italy & Abroad & \\
\hline Charging method & Flat & Volumetric & Volumetric & \\
\hline Recycling rate & High & Low & Medium & \\
\hline Choose your preferred contract & $\square$ & $\square$ & $\square$ & $\square$ \\
\hline
\end{tabular}


electric bills in their households and were over 18 years old) was selected to be representative of the Italian population in terms of gender, age and area of residence. All questionnaires were compiled, and the non-response rate was nil since the respondents had contracts with the market research company.

Regarding the CE, we used the multinomial logit model (MNL) for exploratory purposes. Additionally, we examined a random effect specification by implementing an LC model. Here, in contrast to the traditional MNL, where consumers are assumed to be homogeneous, heterogeneity in consumer preferences for waste collection service attributes was measured using the LC model. Despite the traditional logit, the LC model is more flexible and not subject to the independence from irrelevant alternatives (IIA) (Arrow, 1951). The IIA refers to the fact that the ratio of the probability of choosing one alternative over another is unaffected by the presence or the absence of any additional alternative in the choice set. The LC model relaxes the limitations by offering a particular flexibility to accommodate the respondents' differences in decision strategies and choice consistency, which would otherwise lead to biased utility estimates (Hess et al., 2013). The increasing use of this model has been underpinned by the recognition of the heterogeneity in the respondents' preferences and the desire to make this heterogeneity relevant for marketing segmentation purposes.

The WTP value is derived by dividing the coefficient value of each non-monetary attribute by the coefficient value of the monetary attribute (Yacob and Shuib, 2009):

$\mathrm{WTP}_{\mathrm{j}}=-\beta_{\mathrm{j}} / \beta_{\mathrm{m}}$

where $j$ denotes the $j$ th attribute, and $m$ refers to the monetary attribute. This value of any attribute (other than monetary) is called the implicit price (Hanley and Barbier, 2009). The marginal WTP shows how much the public is willing to pay maximally for a oneunit change in an attribute (e.g., an increase in the level of waste recycling). In this way, it shows the public valuation of each attribute in monetary terms. Because the impact of the attribute is not predetermined, WTP can be either positive or negative. Negative marginal WTP becomes the amount that the respondents are willing to accept as compensation for suffering a utility-decreasing attribute variation.

\section{Results and discussion}

\subsection{Sample characteristics and respondents' behaviour}

As mentioned, the data were collected by a professional company by means of an internet survey, which was administered to an Italian panel of participants. Table 3 shows the descriptive statistics of the respondents' main demographic and socioeconomic characteristics. This table also reports the census data collected in 2011 (the most recently available one since the Italian census is held every ten years). The majority of the respondents are male (52.9\%), and more than one-third of them (35.3\%) are older than 24 and younger than 41 years old. Over half of the respondents have attained a secondary or higher educational level, are employed (58.5\%) and are not members of environmental associations (87.3\%). Additionally, drop-off is the main MW collection system in their areas of residence (51.2\%). The majority of the respondents declare a good perception of the service quality (35.7\%) and believe in their neighbours' commitment to a waste collection scheme (55.1\%). Based on our data, we can state that the sample is diverse in terms of key sociodemographic variables. In general, the sample is younger and has a higher educational level than the average among the citizens of Italy. These characteristics are due to the fact that our sample includes only the respondents who are over 18 years old and in charge of paying their household electric bills. Nevertheless, the data are helpful in understanding the factors affecting the motivations for garbage sorting.

Regarding the question of building a treatment facility in Italy in exchange for a free MW collection service, the preference for not accepting it (58\% versus $42 \%$ ) emerges (see Table 4 ). The percentage changes according to the main motivation associated with domestic sorting.

The participants have also been asked to give an overall judgement about separate waste collection (Table 5). The possible answers range from disagreement (due to the unpleasantness of domestic sorting - first two columns) to enthusiastic agreement

Table 3

Respondent characteristics.

\begin{tabular}{|c|c|c|c|c|}
\hline & & $\mathrm{N}$ & $\%$ & $\%$ (Census data - 2011) \\
\hline \multirow[t]{2}{*}{ Gender } & Male & 534 & 52.9 & 48.5 \\
\hline & Female & 476 & 47.1 & 51.5 \\
\hline \multirow[t]{5}{*}{ Age (years) } & Under 25 & 82 & 8.1 & 24.0 \\
\hline & Between 25 and 40 & 357 & 35.3 & 21.2 \\
\hline & Between 41 and 55 & 310 & 30.7 & 22.8 \\
\hline & Between 56 and 70 & 236 & 23.4 & 17.5 \\
\hline & Over 70 & 25 & 2.5 & 14.5 \\
\hline \multirow[t]{5}{*}{ Educational level } & Primary & 2 & 0.2 & 22.5 \\
\hline & Intermediate grade & 77 & 7.6 & 31.8 \\
\hline & Secondary & 517 & 51.2 & 28.8 \\
\hline & Graduate & 380 & 37.7 & 11.2 \\
\hline & Other & 34 & 3.3 & 5.7 \\
\hline \multirow[t]{3}{*}{ Employed } & Yes & 591 & 58.5 & 46.3 \\
\hline & No & 295 & 29.2 & 31.4 \\
\hline & No (retired) & 124 & 12.3 & 22.3 \\
\hline \multirow[t]{2}{*}{ Environmental association } & Yes & 128 & 12.7 & 2.1 \\
\hline & No & 882 & 87.3 & 97.9 \\
\hline \multirow[t]{2}{*}{ MW collection system } & Kerbside & 493 & 48.8 & \\
\hline & Drop-off & 517 & 51.2 & \\
\hline \multirow[t]{4}{*}{ Perceived service quality } & Poor & 241 & 23.9 & \\
\hline & Fair & 305 & 30.2 & \\
\hline & Good & 361 & 35.7 & \\
\hline & Very good & 103 & 10.2 & \\
\hline \multirow[t]{2}{*}{ Neighbours' commitment } & No & 454 & 44.9 & \\
\hline & Yes & 556 & 55.1 & \\
\hline
\end{tabular}


Table 4

Willingness to accept the location of a treatment facility in Italy in exchange for a free MW collection service, broken down by motivation.

\begin{tabular}{llllll}
\hline Motivation: & No & & \multicolumn{2}{l}{ Yes } \\
\cline { 2 - 3 } \cline { 6 - 6 } & $\mathrm{n}$ & & & $\mathrm{n}$ & $\%$ \\
\hline Lower collective cost & 39 & 48 & & 42 & 52 \\
Lower tariff & 225 & 57 & & 167 & 43 \\
Moral obligation & 324 & 60 & & 213 & 40 \\
Total & 588 & 58 & 422 & 42 \\
\hline
\end{tabular}

(regardless of economic considerations), while the intermediate answers temper the agreement with the function of a diminution or a maximum increase in the MW collection bill. With the aim to distinguish the value that individuals attribute to domestic sorting and their perception of the usefulness of recycling for society as a whole, we have asked about their WTP for an imaginary technical solution enabling the recycling of all waste, the guarantee of regular collection and urban sanitation, and the absence of any negative impact on the environment (Table 5). The WTP is intended for an additional payment (on top of the actual bill) and can therefore be interpreted as the differential value that individuals attribute to the service they currently receive.

Table 5 shows that significantly, the sample is polarised between "recycling enthusiasts" (WTP "even > than $€ 50$ ") and "recycling pragmatists". Similar to Halvorsen (2012) results, over half of the sample (55\%) affirms that separate collection is good, regardless of any economic consideration. The second highest group (35\%) makes a positive judgement on the condition of an economic benefit (WTP " $<€ 0$ "). Only a negligible fraction of the responses lies in the intermediate classes.

Consistent with the findings of previous studies (e.g., Karousakis and Birol, 2008), all classes show a positive WTP for the "magic stick" - they would be willing to contribute economically even if they might be unwilling or not too willing to sort waste at home. As expected, the recycling enthusiasts' mean WTP is the highest $(€ 31.74)$.

It is also interesting to crosscheck the answers with prevalent motivations (Table 5). The respondents who affirm that waste sorting is a moral duty also have a higher WTP although this is not true for those who make their acceptance of sorting conditional to economic benefits. Additionally, 35.3\% of the respondents state that waste sorting is a moral obligation and report their WTP as even more than $€ 50$. From our results, it seems that the respondents derive utility from behaving in accordance with community values in such a way that deserves their peers' approval or corresponds to an ideal model of citizenship (Lejano and de Castro, 2014).

\subsection{Choice experiment results}

The collected data are then analysed econometrically with NLogit $4.0^{\circledR}$, using the following MNL as a starting point for further analysis against the CE background according to our study's objective. In the second analysis, the data are treated with an LC model. Both models, MNL and LC, share the same utility function specifications, summarised in the following equation:

$$
\begin{aligned}
& \mathrm{U}(\mathrm{xi})=\mathrm{ASC}+\mathrm{b}_{1} * \mathrm{DROPOFF}_{\mathrm{i}}+\mathrm{b}_{2} * \mathrm{KERB}_{-} 5_{\mathrm{i}}+\mathrm{b}_{3} * \mathrm{RIC}_{-} \mathrm{HI}_{\mathrm{i}} \\
& +\mathrm{b}_{4} * \text { RIC_LOW } \mathrm{i}+\mathrm{b}_{5} * \text { SITE_IT } \mathrm{i}+\mathrm{b}_{6} * \mathrm{FEE}_{-} \text {FLAT }_{\mathrm{i}} \\
& +\mathrm{b}_{7} * \operatorname{COST}_{\mathrm{i}}
\end{aligned}
$$

where ASC is a dummy of the "none of these" option; DROPOFF is a dummy for waste collection at disposal sites; KERB_5 is another dummy showing kerbside collection of waste every five days; RIC_HI and RIC_LOW are dummies for high and low recycling, respectively; SITE_IT is a dummy for an Italian disposal site; FEE_FLAT is a dummy variable for fee weighted by house value and number of household members; COST is the cost in $€ /$ year levied on households; and $i$ is the $i$ th choice option.

This MNL model clarifies the utility parameter of each attribute that shows public preference weights for choosing a waste management service contract. Given that the parameters are estimated by considering the "none of these" option as a fourth alternative, the alternative specific constant (ASC) utility function is also estimated.

The results of the MNL estimates are reported in Table 6. As measured by McFadden's R-squared index, an overall good fit of the model is indicated (Hensher et al., 2005), and all the coefficients are statistically significant. Using Table 6 , the relative marginal utility of each attribute of the entire sample can be analysed.

All explanatory variables turn out to be significant determinants of respondents' choices, and almost all have the expected signs. Overall, the results of this basic model indicate that most respondents prefer a high rate of recycling (WTP $€ 77$ ) if given the choice, as stated in several previous studies (e.g., Jamal, 2006; Klaiman et al., 2016) (Table 6). According to Czajkowski et al (2014), given that the signs and the relative value of the coefficients reflect their influence on respondents' choices, we can affirm that the coefficient of the low rate of recycling is negative (WTP $€-81$ ), indicating that it decreases the respondents' perceived utility.

Furthermore, the respondents prefer neither door-to-door collection every five days nor waste collection using urban garbage bins. More frequent collection is favoured, as also reported by some studies (e.g., Jamal, 2006). The fee weighted by the house value and the number of household members increases the respondents' perceived utility, but with a lower effect than that of the high rate of recycling, meaning that this attribute increases the respondents' perceived utility, but the effect is lower than that of the charging method. According to Sasao (2004), generally, the NIMBY syndrome is identified when studying the externalities of landfill localisation, but our results show that, ceteris paribus, the respondents prefer a disposal site in Italy. We provide a few possible explanations for this perhaps surprising finding, including

\begin{tabular}{|c|c|c|c|c|c|c|c|c|c|c|c|c|}
\hline & \multirow{2}{*}{\multicolumn{2}{|c|}{ It is a nuisance }} & \multicolumn{8}{|c|}{ It is a good thing, provided that the annual MW bill maximum increase is: } & \multirow{2}{*}{\multicolumn{2}{|c|}{ Total }} \\
\hline & & & \multicolumn{2}{|l|}{$<€ 0$} & \multicolumn{2}{|c|}{ up to $€ 25$} & \multicolumn{2}{|c|}{ up to $€ 50$} & \multicolumn{2}{|c|}{ even $>€ 50$} & & \\
\hline & $\%$ & WTP & $\%$ & WTP & $\%$ & WTP & $\%$ & WTP & $\%$ & WTP & $\%$ & WTP \\
\hline \multicolumn{13}{|l|}{ Motivation: } \\
\hline Lower collective cost & 0.1 & - & 3.6 & 14.44 & 0.9 & 12.78 & 0.3 & 33.33 & 3.2 & 23.59 & 8.0 & 18.40 \\
\hline Lower tariff & 0.7 & 7.14 & 18.0 & 12.06 & 1.4 & 18.57 & 1.7 & 25.29 & 17.0 & 29.33 & 38.8 & 20.36 \\
\hline Moral obligation & 0.5 & 20.00 & 13.4 & 12.85 & 2.3 & 22.83 & 1.7 & 31.18 & 35.3 & 33.63 & 53.2 & 27.74 \\
\hline Total & 1.3 & 11.54 & 35.0 & 12.61 & 4.6 & 19.57 & 3.7 & 28.65 & 55.5 & 31.74 & 100.0 & 24.12 \\
\hline
\end{tabular}

Table 5

Assessment of domestic sorting, motivation and mean WTP $(€)$ for eradicating the MW problem. 
Table 6

Base model and latent class model results.

\begin{tabular}{|c|c|c|c|c|c|c|c|c|c|}
\hline \multirow[t]{3}{*}{ Variable } & \multirow{3}{*}{$\begin{array}{l}\text { MNL } \\
\text { Coeff. (S.E.) }\end{array}$} & \multicolumn{8}{|c|}{ Latent Class Model } \\
\hline & & \multicolumn{2}{|l|}{ Class 1} & \multicolumn{2}{|l|}{ Class 2} & \multicolumn{2}{|l|}{ Class 3} & \multicolumn{2}{|l|}{ Class 4} \\
\hline & & Coeff. (S.E.) & WTP (€/year) & Coeff. (S.E.) & WTP (€/year) & Coeff. (S.E.) & $\begin{array}{l}\text { WTP } \\
(€ / \text { year })\end{array}$ & Coeff. (S.E.) & $\begin{array}{l}\text { WTP } \\
\text { (€/year) }\end{array}$ \\
\hline ASC & $-2.14(0.08)^{* * *}$ & $-3.01(0.16)^{* * *}$ & 1 & $-6.40(0.43)^{* * *}$ & 1 & $-0.59(3.47)$ & 1 & $-0.87(0.29)^{* * *}$ & 1 \\
\hline COST & $-0.01(0.00)^{* * * *}$ & $-0.01(0.00)^{* * *}$ & 1 & $-0.02(0.00)^{* * *}$ & 1 & $-0.01(0.01)$ & I & $-0.01(0.00)^{* * *}$ & 1 \\
\hline DROPOFF & $-0.34(0.06)^{* * *}$ & $-0.85(0.10)^{* * *}$ & -85 & $-0.95(0.21)^{* * *}$ & -47.5 & $5.49(2.24)^{* * *}$ & I & $-0.39(0.19)^{* * *}$ & -39 \\
\hline KERB_5 & $-0.44(0.06)^{* * * *}$ & $-0.62(0.10)^{* * *}$ & -62 & $-1.85(0.31)^{* * *}$ & -92.5 & $1.36(3.55)$ & i & $-1.06(0.27)^{* * *}$ & -106 \\
\hline SITE_IT & $0.19(0.06)^{* * *}$ & $0.04(0.11)$ & 1 & $-0.74(0.34)^{* * *}$ & -37 & $-0.54(2.05)$ & i & $0.96(0.25)^{* * *}$ & 96 \\
\hline FEE_FLAT & $0.23(0.07)^{* * *}$ & $1.03(0.14)^{* * *}$ & 103 & $1.15(0.48)^{* * * *}$ & 57.5 & $-0.34(2.15)$ & I & $-0.37(0.29)$ & 1 \\
\hline RIC_HIGH & $0.77(0.06)^{* * *}$ & $1.50(0.12)^{* * *}$ & 150 & $-0.08(0.27)$ & 1 & $2.18(2.15)$ & i & $0.38(0.25)$ & 1 \\
\hline RIC_LOW & $-0.81(0.06)^{* * *}$ & $-1.23(0.09)^{* * *}$ & -123 & $-0.55(0.16)^{* * *}$ & -27.5 & $-0.77(1.49)$ & l & $-2.22(0.37)^{* * *}$ & -222 \\
\hline Average probability & 0.59 & & 0.19 & & 0.04 & & 0.18 & & \\
\hline \multicolumn{10}{|c|}{ Theta in class probability model: } \\
\hline South_IT & & \multicolumn{2}{|l|}{$0.20(0.24)$} & \multicolumn{2}{|l|}{$0.66(0.28)^{* * *}$} & \multicolumn{2}{|l|}{$-3.85(1.13)^{* * *}$} & \multicolumn{2}{|l|}{ fixed parameter } \\
\hline Incinerator & & \multicolumn{2}{|l|}{$-0.76(0.30)^{* * *}$} & \multicolumn{2}{|l|}{$-0.66(0.40)$} & \multicolumn{2}{|l|}{$0.24(0.70)$} & \multicolumn{2}{|l|}{ fixed parameter } \\
\hline Landfill & & \multicolumn{2}{|l|}{$0.46(0.20)^{* * *}$} & \multicolumn{2}{|l|}{$0.95(0.25)^{* * *}$} & \multicolumn{2}{|l|}{$0.82(0.39)^{* * *}$} & \multicolumn{2}{|l|}{ fixed parameter } \\
\hline
\end{tabular}

***Significant at a 95\% confidence level.

the desire to avoid environmental damages abroad and a concern about the effectiveness of waste management activities performed by others. Finally, as expected and postulated by the consumer theory, the utility function coefficient associated with the cost of the waste collecting service is negative (Sakata, 2007); the consumer prefers the less expensive alternative, ceteris paribus.

As stated, to overcome the IIA assumption and provide more insights into the respondents' heterogeneity, we use the LC model. For the estimation of the LC model, we consider the previous utility function. According to the statistical parameters or the criteria taken into consideration (log likelihood [LL] function, Akaike information criteria [AIC], Bayesian information criteria [BIC], Hannan-Quinn information criteria [HQIC] and McFadden pseudo $\mathrm{R}$-squared index), the model with four classes should be preferred to the model with three classes (Table 7). In the LC model, we integrate a number of socioeconomic and behavioural variables of the respondents in an attempt to provide a better explanation of the class probability model. The results for the LC- 4 model are reported in Table 7.

The LC-4 model results (Table 7) show that all coefficients of class 1 are statistically significant at a 95\% confidence level $(\mathrm{p}<0.05)$, apart from the Italian disposal site attributes. Regarding class 2 , only the coefficient of the high recycling rate attributes is not statistically significant ( $p>0.05$ ). The coefficients for class 3 are all insignificant except for the use of open-access street bins. For class 4 , the only insignificant attributes are the high rate of recycling and the fee weighted by the house value and the number of household members. The ASC is statistically significant for all classes, except class 3. It is also negative, meaning that there are preferences for the "none" option, which could not be explained by the variables contained in this model.

Although the respondents seem mainly to (1) be in favour of recycling, (2) have a negative WTP for a low recycling rate and (3)

Table 7

Statistical indicators for LC models' comparison.

\begin{tabular}{lllll}
\hline & LC-2 & LC-3 & LC-4 & LC-5 \\
\hline LL & -6279.171 & -6143.702 & -5878.244 & -5937.867 \\
AIC & 2.0806 & 2.041 & 1.9595 & 1.9848 \\
BIC & 2.1083 & 2.088 & 2.0248 & 2.069 \\
HQIC & 2.0902 & 2.058 & 1.9822 & 2.0140 \\
McFadden pseudo $\mathrm{R}^{2}$ & 0.252 & 0.269 & 0.300 & 0.293 \\
\hline
\end{tabular}

blame the lack of effort, there are further important characterisations to make among the classes. First, the intensity of the coefficients varies among the groups and consequently, the relative importance of the recycling-related attributes. Second, the main motivation underlying the support for recycling seems to differ among the groups.

The members of class 1 (with 59.2\% estimated probability) are more concerned about a high rate of recycling. In fact, they are willing to pay $€ 150$ to reach a high waste recycling rate, pointing out the existence of a strong "warm glow" among this group of respondents. Similar to Halvorsen (2012) findings, their strongest motivation for recycling could be their willingness to preserve their homeland from disposal sites, respect their community and improve the environmental quality, whereas the economic cost is rather unimportant (within the range proposed). Consequently, for this group of respondents, warm glow is able to provide an intrinsic utility. They seem convinced that a high waste recycling rate would ensure that society gains the maximum net benefit (Jamal, 2006). Since the stated preference methods (e.g., the CE used in this study) are also the primary means of valuing this kind of benefit (Sakata, 2007), providing the opportunity to elicit a deeper understanding of different waste management attributes, the WTP amount obtained seems to be an adequate empirical estimation of warm glow despite its high value. From our findings, we can also state that the choice of collection methods is relatively less a priority. However, the respondents favour kerbside collection every three days. Furthermore, they express a strong preference for a charging method that reflects personal wealth rather than a volumetric measurement. For this group, which constitutes the majority, MW is fundamentally a "collective evil" and requires a collective effort, whose economic burden requires equitable sharing patterns. As the ASC captures the effects of perceived utility on any attribute that is not included in choice-specific attributes, we can state that in this class, its significant and negative coefficient indicates that the negative utility impact occurs in any move away from the status quo. Furthermore, it seems that this group has a higher share of people living in municipalities where a landfill instead of an incinerator exists, in comparison to class 4 (the base case). The members of class 1 could be described as "green fundamentalists".

The members of class 2 (with 19.2\% estimated probability) have weaker preferences for the rate of recycling although they declare a negative WTP for the low rate of recycling (€-27.5) and opt to focus on MW collection service reliability and cost-effectiveness. They 
strongly favour kerbside collection, provided that it is done every three days; in fact, their WTP is negative for the other collection services. As stated, they blame the insufficient effort in separate collection but almost equally seem far from advocating green fundamentalism. In fact, while insignificant, some evidence indicates that high recycling is not preferred by this group of respondents. Separate collection is accepted and promoted but not at any cost; perhaps it is regarded mostly as a way to reduce individual bills and spare collective resources. This group's members are clearly affected by NIMBY; in fact, their statement about the Italian location of treatment facilities is negative (WTP: $€-37)$. Moreover, the flat charging method - a flat fee based on the house value and the number of household members - is another variable that increases the respondents' perceived utility. Similar to class 1 , in class 2 , the ASC is significant and negative, indicating a strong propensity to avoid selecting the proposed alternatives due to factors not explained by the model. This group seems to comprise more Southern Italy residents who live in municipalities with landfills. They could be called "NIMBY supporters".

At first glance, class 3 seems to be more difficult to characterise (with 3.9\% estimated probability). The only statistically significant variable is the waste collection with drop-off bins located in some areas of the street at a convenient distance. All the other variables are insignificant. In class 3, Southern Italians are mainly absent. This group's members are "kerbside collection lovers".

The aversion towards the low recycling rate collection scheme is the strongest attribute of class 4 (with $17.7 \%$ estimated probability), and the connected WTA (negative WTP) is high ( $€-222)$. This group is also concerned about the drop-off collection scheme and waste collection every five days. Its preference for the location of treatment facilities in Italy is strong, and its WTP is $€ 96$, but the probable reason is interesting; rather than a practical motivation inspired by cost-effectiveness, we suggest that the idea of "punishing" those who are less committed to the common good could be the main reason in this case. The members could be named "selfsufficient citizens".

Although we have included socio-demographic, structural and behavioural variables in the LC model to explain class probability (as previously described), they are not generally significant in accounting for the probability of class membership. Age groups, education level and occupation do not determine belonging to one class instead of another. Nevertheless, place of residence seems to partially influence class membership.

\section{Conclusions}

Our study offers several results that shed new light on the importance of recycling in the context of MW management, either from an Italian perspective or for the international reader.

In the first place, people seem to have substantially digested the idea that domestic sorting of waste is required and practise it increasingly as routine behaviour. While they express a satisfactory judgement among themselves and on their individual levels of commitment, they are still somewhat critical about the intensity of the effort provided by the community as a whole.

Indirectly, our results confirm other researchers' findings about the "crystallisation" of social norms in routine behaviour and the declining importance of self-expression and motivational issues after the initial phase (e.g., Zheng et al., 2017). While in the initial phases, a positive vision prevails (i.e., individuals aim at distinguishing themselves as "good recyclers" [compared with the majority that fail to do so] and feeling a warm glow from recycling), consolidation brings about a negative approach (blaming those who do not commit themselves adequately, assuming that the standard behaviour includes a certain level of recycling effort).
While expressing a critical view about their neighbours' engagement, they also seem to express a strong preference for MW management methods that lead to a substantial increase in the levels of recycling. The WTP is high in general; it is very high (and negative) with respect to the low intensity of waste separation, which probably means that the majority of people regard the effort they actually provide as not excessive for them and perhaps could be enhanced.

Moreover, a mean WTP of $€ 77 /$ year per family to achieve a high recycling performance is quite an impressive value, especially considering that recycling performance in Italy - particularly in some areas - is already rather high. However, it should be noted that in a hypothetical situation, such as a $C E$, the cognitive component might have a lower weight than in a real situation. Consequently, we can state that this WTP could be considered an adequate empirical estimation of the warm-glow effect produced by recycling.

We also suggest that enthusiasm about the usefulness of recycling and domestic sorting has declined. Motivation has become less ideological and more practical; the willingness to further increase efforts is less unconditional and (as reported) has become a routine. In fact, many MW management operators whom we have interviewed to prepare for this study have confirmed the difficulty of maintaining high levels of commitment.

The limitation of this study is first of all, its use of the online survey. The online survey offers many advantages over traditional surveys; primarily, it requires fewer resources than the traditional ones. However, we acknowledge that it also has disadvantages (Callegaro et al., 2015), such as limited sampling and respondent availability (Wright, 2005). In this regard, the use of other samples may represent interesting extensions of this research path.

To be able to conclude that our findings can be used for statistical inference, it will be necessary to proceed with further experiments based on the analysis of the behaviour of citizens from other countries. Nonetheless, in the context of heterogeneous respondents, the LC model analysis proves to be particularly suited to the investigation of citizens' preferences, at least with reference to the Italian case study. To a certain extent, this model helps define information strategies that could be useful to public decision makers. In fact, this research provides some interesting results that can be used by policymakers in organising the MW management system and providing incentives to citizens in order to improve the recycling outcomes. Moreover, institutional decision makers with targets for increased recycling can take advantage of the preferences expressed by the respondents by promoting and enhancing awareness of the benefits of such action among the other citizens, providing them with specific information that facilitates a high recycling rate.

\section{Declarations of interest}

None.

\section{References}

Aadland, D., Caplan, A., 2006a. Cheap talk reconsidered. New evidence from CVM. J. Econ. Behav. Organ. 60, 562-578.

Aadland, D., Caplan, A., 2006b. Curbside recycling: waste resource or waste of resource? J. Pol. Anal. Manag. 25 (4), 855-874.

Abbott, A., Nandeibam, S., O'Shea, L., 2013. Recycling: social norms and warm-glow revisited. Ecol. Econ. 90, 10-18.

Abrahamse, W., Steg, L., 2013. Social influence approaches to encourage resource conservation: a meta-analysis. Global Environ. Change 23, 1773-1785.

Adamowicz, W., Louviere, J., Williams, M., 1994. Combining revealed and stated preference methods for valuing environmental amenities. J. Environ. Econ. Manag. 26, 271-292.

Adamowicz, W., Boxall, P., Williams, M., Louviere, J., 1998. Stated preferences approaches to measuring passive use values. Am. J. Agric. Econ. 80, 64-75. 
Andersson, M., von Borgstede, C., 2010. Differentiation of determinants of low-cost and high-cost recycling. J. Environ. Psychol. 30, 402-408.

Andreoni, J., 1990. Impure altruism and donations to public goods: a theory of warm-glow giving. Econ. J. 100, 464-477.

Arrow, K.J., 1951. Social Choice and Individual Values. Yale University Press, New Haven.

Boxall, P.C., Adamowicz, W.L., Swait, J., Williams, M., Louviere, J., 1996. A comparison of stated preference methods for environmental valuation. Ecol. Econ. 18 (3) $243-253$.

Brekke, K.A., Kverndokk, K., Nyborg, K., 2003. An economic model of moral motivation. J. Publ. Econ. 87, 1967-1983.

Bruvoll, A., Halvorsen, B., Nyborg, K., 2002. Households' recycling efforts. Resour. Conserv. Recycl. 36, 337-354.

Callegaro, M., Manfreda, K.L., Vehovar, V., 2015. Web Survey Methodology. Sage.

Cecere, G., Mancinelli, S., Mazzanti, M., 2014. Waste prevention and social preferences: the role of intrinsic and extrinsic motivations. Ecol. Econ, 107, 163-176.

Chan, L., Bishop, B., 2013. A moral basis for recycling: extending the theory of planned behaviour. J. Environ. Psychol. 36, 96-102.

Czajkowski, M., Kądziela, T., Hanley, N., 2014. We want to sort! Assessing households' preferences for sorting waste. Resour. Energy Econ. 36 (1), 290-306.

Czajkowski, M., Hanley, N., Nyborg, K., 2017. Social norms, morals and self-interest as determinants of pro-environmental behavior. The case of household recycling. Environ. Resour. Econ. 66, 647-670.

da Cruz, N.F., Ferreira, S., Cabral, M., Sim๕es, P., Marques, R.C., 2014. Waste Manag. 34, 298-308.

Ferreira, S., Maques, R.C., 2015. Contingent valuation method applied to waste management. Resour. Conserv. Recycl. 99, 111-117.

Giaccaria, S., Frontuto, V., 2012. Perceived health status and environmental quality in the assessment of external cost of waste disposal facilities. An empirica investigation. Waste Manag. Res. 30 (8), 864-870.

Halvorsen, B., 2012. Effects of norms and policy incentives on household recycling: an international comparison. Resour. Conserv. Recycl. 67, 18-26.

Hanley, N., Barbier, E.B., 2009. Pricing Nature. Cost Benefit Analaysis and Environmental Policy. Edward Elgar Publishing Limited, Cheltenham, UK.

Hanley, N., MacMillan, D., Wright, R., Bullock, C., Simpson, I., Parsisson, D. Crabtree, B., 1998. Contingent valuation versus choice experiments: estimating the benefits of environmentally sensitive areas in Scotland. J. Agric. Econ. 49, $1-15$.

Hanley, N., Mourato, S., Wright, R.E., 2001. Choice modelling approaches: a superior alternative for environmental valuation? J. Econ. Surv. 15, 435-462.

Heller, M., Vatn, A., 2017. The divisive and disruptive effect of a weight-based waste fee. Ecol. Econ. 131, 275-285.

Hensher, D., Rose, J., Greene, W., 2005. Applied Choice Analysis: a Primer. Cambridge University Press.

Hess, S., Stathopoulos, A., Campbell, D., O'Neill, V., Caussade, S., 2013. It's not that I don't care, I just don't care very much: confounding between attribute nonattendance and taste heterogeneity. Transportation 40, 583-607.

ISPRA, 2013. Rapporto rifiuti urbani, edizione 2013. Istituto Superiore per la protezione e la ricerca ambientale. Italian Institute for Environmental Protection and Research), ISPRA settore editoria, Roma.

Jamal, O., 2006. Economic valuation of household preference for solid waste management in Malaysia: a choice modeling approach. Int. J. Manag. Stud. 13 (1), $1-23$.

Jin, J., Wang, Z., Ran, S., 2006. Comparison of contingent valuation and choice experiment in solid waste management in Macao. Ecol. Econ. 57, 430-441.

Karousakis, K., Birol, E., 2008. Investigating household preferences for kerbside recycling services in London: a choice experiment approach. J. Environ. Manag. 88 (4), 1099-1108.

Kinnaman, T.C., 2014. Determining the socially optimal recycling rate. Resour.
Conserv. Recycl. 85, 5-10.

Kirakozian, A., 2016. One without the other? Behavioural and incentive policies for household waste management. J. Econ. Surv. 30 (3), 526-551.

Klaiman, K., Ortega, D.L., Garnache, C., 2016. Consumer preferences and demand for packaging material and recyclability. Resour. Conserv. Recycl. 115, 1-8.

Lancaster, K.J., 1966. A new approach to consumer theory. J. Polit. Econ. 7 (2), $132-157$.

Lejano, R.P., de Castro, F.F., 2014. Norm, network and commons. The invisible hand of the community. Environ. Sci. Pol. 36, 73-85.

Matthies, E., Selge, S., Klöckner, C., 2012. The role of parental behaviour for the development of behaviour-specific environmental norms: the example of recycling and re-use behaviour. J. Environ. Psychol. 32, 277-284.

McFadden, D., 1974. The measurement of urban travel demand. J. Publ. Econ. 3 (4), 303-328.

Pek, C.K., Jamal, O., 2011. A choice experiment analysis for solid waste disposal option: a case study in Malaysia. J. Environ. Manag. 92 (11), 2993-3001.

Rege, M., 2004. Social norms and private provision of public goods. J. Publ. Econ. Theor. 6, 65-77.

Sakata, Y., 2007. A choice experiment of the residential preference of waste management services. The example of Kagoshima city, Japan. Waste Manag. 27 (5), 639-644.

Sasao, T., 2004. An estimation of the social costs of landfill siting using a choice experiment. Waste Manag. 24 (8), 753-762.

Shaw, P.J., 2008. Nearest neighbour effect in kerbside household waste recycling. Resour. Conserv. Recycl. 52, 775-784.

Sidique, S., Lupi, F., Joshi, S.V., 2010. The effects of behavior and attitudes on drop-off recycling activities. Resour. Conserv. Recycl. 54, 163-170.

Struk, M., 2017. Distance and incentives matter: the separation of recyclable municipal waste. Resour. Conserv. Recycl. 122, 155-162.

Tan, O., Duan, H., Liu, L., Yang, J., Li, J., 2018. Rethinking residential consumers' behavior in discarding obsolete mobile phones in China. J. Clean. Prod. 195, 1228-1236.

Tong, X., Nikolic, I., Dijkhuizen, B., van den Hoven, M., Minderhoud, M., Wäckerlin, N., Wang T. Dongyan, T, 2018. Behaviour change in post-consumer recycling: applying agent-based modelling in social experiment. J. Clean. Prod. $187,1006-1013$.

Van den Bergh, J., 2008. Environmental regulation of households. An empirical review of economic and psychological factors. Ecol. Econ. 66, 559-574.

Varotto, A., Spagnolli, A., 2017. Psychological strategies to promote household recycling. A systematic review with meta-analysis of validated field interventions. J. Environ. Psychol. 51, 168-188.

Viscusi, W.K., Huber, J., Bell, J., 2011. Promoting recycling: private values, social norms and economic incentives. Am. Econ. Rev.: Pap. Proc. 101 (3), 65-70.

Wan, C., Qiping Shen, G., Yu, A., 2013. The role of perceived effectiveness of policy measures in predicting recycling behaviour in Hong Kong. Resour. Conserv. Recycl. 83, 141-151.

Wang, Z., Guo, D., Wang, X., 2016. Determinants of resident's e-waste recycling behaviour intentions: evidence from China. J. Clean. Prod. 127, 850-860.

Wright, K.B., 2005. Researching Internet-based populations: advantages and disadvantages of online survey research, online questionnaire authoring software packages, and web survey services. J. Computer-Mediated Commun. 10 (3), JCMC1034.

Yacob, M.R., Shuib, A., 2009. Assessing the preference heterogeneity in marine ecotourism attributes by using choice experiment. Int. J. Econ. Manag. 3 (2), 367-384.

Zheng, P., Zhang, K., Zhang, S., Wang, R., Wang, H., 2017. The door-to-door recycling scheme of household solid wastes in urban areas: a case study from Nagoya, Japan. J. Clean. Prod. 163, 366-S373. 